2. Isbin, H. S., J. E. Moy, and A. J. R. Cruz, ibid., 3, 361365 (1957).

3. Zaloudek, F. R., H W-68934 Rev., Hanford Atomics Works (1961).

4. Fauske, H. K., Sc.D. thesis, Univ. Trondheim, Norway (1961); also ANL 6633.

5. Moody, F. J., Trans. Am. Soc. Mech. Engrs., 87C, 134 (1965).

6. Levy, S., ibid., 53.

7. Meyer, J. E., WAPD-BT-20 (1960).

8. Baker, O., Oil Gas J., 53, No. 12, 185 (1954).

9. Vance, W. H., Ph.D. thesis, Univ. Washington, Seattle
(1962).

10. Prigogine, I., "Introduction to Thermodynamics of Irreversible Processes," Interscience, New York (1955).

11. Stodola, A., "Steam and Gas Turbines," McGraw-Hill, New York (1927).

12. Cruver, J. E., Ph.D. thesis, Univ. Washington, Seattle (1963).

13. James, R., Proc. Inst. Mech. Engrs., (1962).

14. Martinelli, R. C., and D. B. Nelson, Trans. Am. Soc. Mech. Engrs., 70,695 (1948).

Manuscript received January 8, 1965; revision received May 27, 1966 paper accepted May 31, 1966. Paper presented at A.I.Ch.E. Houston meeting.

\title{
Vapor-Liquid Equilibrium for the System
}

\section{Hydrogen-Benzene-Cyclohexane- $n$-Hexane}

\author{
ALAN J. BRAINARD and G. BRYMER WILLIAMS \\ University of Michigan, Ann Arbor, Michigan
}

\begin{abstract}
This paper presents vapor-liquid equilibrium data for the system hydrogen-benzene-cyclohexane-n-hexane over the pressure range of 500 to 2,000 lb./sq.in.abs. and the temperature range of $200^{\circ}$ to $300^{\circ} \mathrm{F}$. Experimental equipment was constructed that was capable of operating at pressures of $3,000 \mathrm{lb}$./sq.in.abs. and at temperatures of $400^{\circ} \mathrm{F}$. A static equilibrium cell, which had a sample port for both the liquid and vapor phases, was employed. Separation of the hydrogen from the hydrocarbons by means of a liquid nitrogen cold trap was utilized before performing the hydrocarbon analyses on a mass spectrometer. Three hydracarbon mixtures were charged to the equilibrium cell, and for each charge, isotherms of $200^{\circ}, 250^{\circ}$, and $300^{\circ} \mathrm{F}$. were run for equilibrium pressures of 500, 1,000, 1,500 and 2,000 lb./sq.in.abs. These thirty-six quaternary equilibrium runs resulted in a total of one hundred and forty-four equilibrium data points. In addition, four binary equilibrium runs were determined both for the hydrogen-benzene and hydrogen-cyclohexane systems. A modified version of the Chao-Seader correlation was used to predict the data. This correlation was able to predict all the quaternary equilibrium ratios with an average deviation of $4.86 \%$.
\end{abstract}

The need for basic data on the vapor-liquid equilibrium in hydrogen-hydrocarbon systems has become more important recently, especially in the design of commercial hydrocracking units. The bulk of the published literature in this area has appeared within the past twenty years, and it is likely that there is more interest and activity in this area than ever before.

The wide variety of possible hydrogen-hydrocarbon systems, as well as temperature and pressure conditions that may be of interest, points out the need of a prediction technique that will handle these systems. Physical chemists and physicists have been developing models of the gaseous and liquid states that enable one to predict the properties of these states.

For the most part, engineers have turned to empirical approaches to the subject, and a number of generalized charts have been developed. The NGAA charts (1), the

Alan J. Brainard is with Esso Research Laboratories, Baton Rouge, Louisiana.
Kellogg charts (2), and the chart of Hougen et al. (3) are representative of these correlations.

Hydrogen-hydrocarbon systems present interesting experimental challenges. Over quite wide temperature and pressure conditions one is dealing with very small quantities of some of the substances in the system in each of the equilibrium phases. Under the temperature and pressure conditions of this investigation, small hydrogen liquid phase concentrations and small hydrocarbon vapor phase concentrations resulted at equilibrium. It is felt that the experimental approach presented in this paper avoids some of the inherent difficulties present in a normal analysis scheme.

\section{EQUIPMENT}

An overall schematic representation of the experimental apparatus is shown in Figure 1. For the sake of description, the system will be divided into three sections: the charging section, the equilibrium section, and the sampling section. 


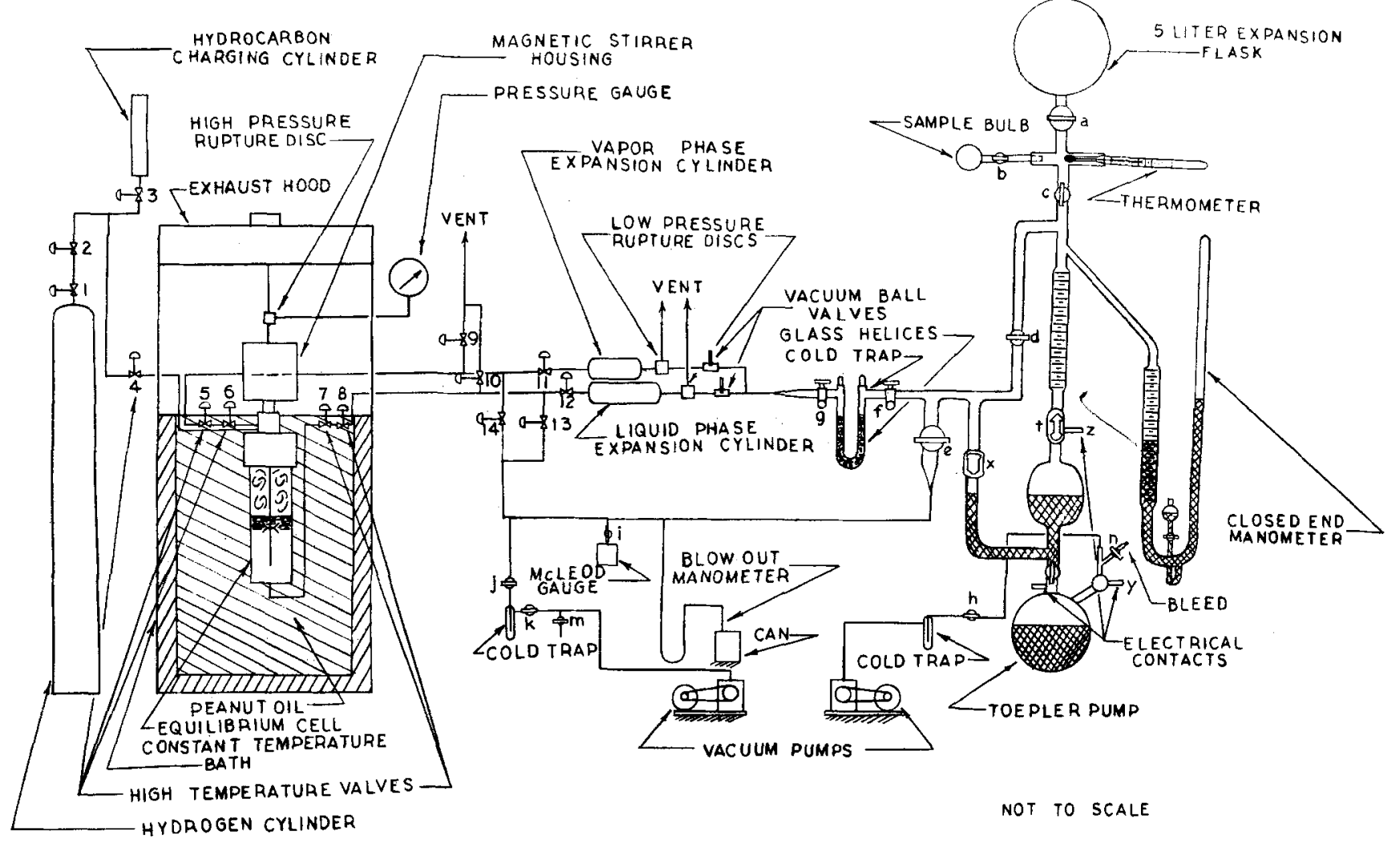

Fig. 1. Schematic representation of experimental equipment.

\section{Charging Section}

Hydrogen was charged directly from a high-pressure cylinder into the equilibrium cell. Becanse the pressures studied in this investigation were less than $2,000 \mathrm{lb} . / \mathrm{sq} . i n . a b s$. , there was no need for a gas compressor. The hydrocarbons entered the equilibrium cell by a combination of gravity and vacuum flow. The hydrogen used in this investigation was the ultra-pure grade supplied by the Matheson Company. The hydrocarbons used were the research grade of the Phillips Petroleum Company. Table 1 lists the purities of these materials.

The hydrocarbon purities were established by freezing point determinations of a representative sample of the hydrocarbon lots. No attempt was made to purify further any of these materials.

All of the valves, tees, and lines in the charging section, the equilibrium section, and the sampling section up to the stainless steel expansion cylinders were standard $1 / 4$-in. stainless steel, high-pressure items.

\section{Equilibrium Section}

The equilibrium cell, which had a volume of $\sim 200 \mathrm{cc}$., was totally immersed in a constant temperature bath. A sample

Table 1. Purities of Materials Used in This Study

Compound Stated purity (mole \%)

Major impurity

Hydrogen

Benzene

Less than 20 p.p.m. impurities

Cyclohexane 99.89

$n$-Hexane

99.99

99.97
Toluene

2,4-Dimethylpentane and 2,2-diethylpentane Methylcyclopentane of the vapor phase could be withdrawn from the cell by using valves 5 and 6 and a liquid phase sample could be taken with valves 7 and 8 . All valves used in the high-pressure portion had Teflon packings. The bath temperature was maintained by using hairpin resistance heaters in conjunction with a temperature controller. Cell temperatures were measured by a thermometer immersed in the bath, and were known and maintained within $\pm 0.5^{\circ} \mathrm{F}$. Cell pressures were read from a Bourdon tube pressure gauge which had been calibrated against a dead weight tester and which are accurate within $\pm 2 \mathrm{lb}$./ sq.in.abs.

Agitation of the cell's contents was provided by a magnetically actuated stirrer. The disk stirrer which was employed would undergo a $1 \frac{1}{2}-\mathrm{in}$, vertical cycle twice every second.

\section{Somple Section}

The sampling section consisted primarily of the expansion cylinders, the cold trap used to separate the hydrogen from the hydrocarbons, a Toepler pump, a collecting burette, and various collecting bulbs. The expansion cylinders served to lower the sample pressure from that of the equilibrium mix-

Table 2. Comparison Between Known Liquid Composition and Consecutive Mass Spectrometer Analysis

\begin{tabular}{cccccccc} 
& \multicolumn{1}{c}{ Consecutive liquid } & & & phase sample results \\
Charge composition & 1 & 2 & 3 & 4 & 5 & 6
\end{tabular}

$\begin{array}{llllllll}x^{\prime} \text { Benzene } & 0.478 & 0.480 & 0.479 & 0.480 & 0.484 & 0.476 & 0.478 \\ x^{\prime} \text { 'Cyciohexane } & 0.393 & 0.392 & 0.390 & 0.391 & 0.386 & 0.393 & 0.393 \\ x^{\prime} n \text {-Hexane } & 0.129 & 0.128 & 0.131 & 0.129 & 0.130 & 0.131 & 0.129\end{array}$

The prime refers to hydrogen-free composition. 
Tabie 3. Summary of Quaternary Experimental Results at $200^{\circ} \mathrm{F}$.

Pressure,

\begin{tabular}{|c|c|c|c|c|c|c|c|c|}
\hline $\begin{array}{l}\text { Pressure, } \\
\text { lb./sq. in. abs }\end{array}$ & $x$ Hydrogen & $x_{\text {Benzene }}$ & $x$ Cyclohexane & $x_{n \text {-Hexane }}$ & $K_{\text {Hydrogen }}$ & $K_{\text {Benzene }}$ & $K_{\text {Cyclohexane }}$ & $K_{n \text {-Hexane }}$ \\
\hline 527 & 0.0235 & 0.3935 & 0.3298 & 0.2532 & 40.00 & 0.0582 & 0.0546 & 0.0794 \\
\hline 1,032 & 0.0450 & 0.3859 & 0.3225 & 0.2476 & 21.46 & 0.0329 & 0.0309 & 0.0448 \\
\hline 1,536 & 0.0655 & 0.3766 & 0.3156 & 0.2423 & 14.84 & 0.0287 & 0.0269 & 0.0390 \\
\hline 1,997 & 0.0849 & 0.3688 & 0.3090 & 0.2373 & 11.52 & 0.0226 & 0.0212 & 0.0307 \\
\hline 507 & 0.0204 & 0.4738 & 0.3786 & 0.1272 & 46.13 & 0.0593 & 0.0590 & 0.0856 \\
\hline 1,022 & 0.0401 & 0.4608 & 0.3754 & 0.1237 & 24.17 & 0.0311 & 0.0308 & 0.0473 \\
\hline 1,478 & 0.0580 & 0.4515 & 0.3671 & 0.1234 & 16.82 & 0.0240 & 0.0247 & 0.0379 \\
\hline 1,985 & 0.0756 & 0.4440 & 0.3619 & 0.1185 & 12.94 & 0.0213 & 0.0215 & 0.0335 \\
\hline 520 & 0.0245 & 0.2341 & 0.5558 & 0.1856 & 38.16 & 0.0684 & 0.0609 & 0.0825 \\
\hline 1,012 & 0.0455 & 0.2277 & 0.5441 & 0.1827 & 21.25 & 0.0356 & 0.0308 & 0.0442 \\
\hline 1,482 & 0.0651 & 0.2243 & 0.5327 & 0.1779 & 14.98 & 0.0270 & 0.0232 & 0.0342 \\
\hline 1,987 & 0.0854 & 0.2193 & 0.5234 & 0.1719 & 11.46 & 0.0239 & 0.0209 & 0.0308 \\
\hline
\end{tabular}

ture (at times as great as $2,000 \mathrm{lb}$./sq.in.abs.) to a subatmospheric value. The expansion cylinder enhanced vaporization of the liquid phase sample trapped between valves 7 and 8 .

The cold trap, where the actual separation of the hydrogen from the hydrocarbons occurred, was simply a U tube filled with glass helicies to a depth of about 6 in.

The Toepler pump served to move gases through the cold trap and then into the collecting burette which was connected directly to its discharge side. For a given sample, this pump would operate at a rate of about $1 \mathrm{cycle} / 30 \mathrm{sec}$. for a period of 20 to $40 \mathrm{~min}$.

The remainder of the collecting system consisted of a calibrated glass burette, an expansion flask, and a sample bulb. All stopcocks in the glass section were of the hollow plug oblique bore vacuum type of either a 4 - or 8 -mm. diameter. These stopcocks were greased with a stopcock grease, Nonaq, supplied by Fisher Scientific, which was insoluble in the hydrocarbons used in this study. Although the vacuum properties of this grease were not as satisfactory as those of other commercial greases, all other greases tried absorbed either one or all of the hydrocarbons used in this research and therefore could not be used.

\section{EXPERIMENTAL PROCEDURE}

Once the materials had been charged to the equilibrium cell (120 cc. of hydrocarbons were charged) and the magnetic stirrer had been activated, the bath heaters were turned on and the bath and its contents were brought to the desired equilibrium temperature. After this temperature level had been reached, the magnetic stirrer was allowed to operate for a period which was never less than $12 \mathrm{hr}$. Preliminary runs had shown that between 4 and $6 \mathrm{hr}$. were necessary for the liquid phase to come to equilibrium for given temperature and pressure conditions and system geometry.

The magnetic stirrer was then turned off and a sample of the liquid phase was removed by using valves 7 and 8 . This initial sample was not taken to be representative of the contents of the cell, for preliminary runs had shown that concentration gradients existed in the line of high-pressure tubing between the bottom of the equilibrium cell and valve 7, even after four days of agitation. As a result, this sample and four additional samples were vented. (This was a volume about twice as large as the holdup in the high-pressure line.) The sampling system was reevacuated to a pressure of 10 microns for a 1-hr. period and then the sample which was removed from the cell was taken to be representative of the equilibrium liquid phase.

The liquid phase sample was then allowed to expand into the expansion cylinders and then to enter slowly the cold trap which was maintained at liquid nitrogen temperature. The hydrocarbons would then solidify in the cold trap and the hydrogen would be moved by the Toepler pump into the collecting burette. The pressure of the entire liquid phase sampling line would be about 20 microns when the Toepler pump was turned off. The pressure of the hydrogen in the liquid phase sample was then read on the closed end manometer with a cathetometer which was capable of reading pressure differences as low as 50 microns. The calibrated collecting burette was used to determine the sample volume and a thermometer associated with the burette was used to measure the sample temperature.

Once the pressure, volume, and temperature readings of the hydrogen had been obtained, the hydrogen was vented and the gas burette was reevacuated. Stopcock $f$ was then opened and the hydrocarbons were allowed to sublimate and enter the 5-liter expansion flask and the gas burette. The Toepler pump was employed to move all of the hydrocarbons from the cold trap into the desired collecting volumes. Preliminary runs had shown that if the contents of the 5-liter expansion flask were sampled immediately, concentration gradients were present and a nonrepresentative hydrocarbon sample would result. This problem was solved by allowing the hydrocarbons to reexpand up to stopcock $g$ and then to be repumped

Table 4. Summary of Quaternary Experimental Results at $250^{\circ} \mathrm{F}$.

Pressure,

$\begin{array}{rrrr}\text { lb./sq. in. abs } & \text { xHydrogen } & \text { xBenzene } & x_{\text {Cyclohexan }} \\ & & & \\ 510 & 0.0255 & 0.3935 & 0.3287 \\ 1,024 & 0.0511 & 0.3834 & 0.3202 \\ 1,535 & 0.0741 & 0.3742 & 0.3124 \\ 1,993 & 0.0976 & 0.3646 & 0.3045 \\ 555 & 0.0255 & 0.4662 & 0.3830 \\ 1,047 & 0.0464 & 0.4562 & 0.3748 \\ 1,492 & 0.0682 & 0.4458 & 0.3662 \\ 1,995 & 0.0897 & 0.4334 & 0.3580 \\ 519 & 0.0258 & 0.2266 & 0.5660 \\ 1,016 & 0.0509 & 0.2237 & 0.5487 \\ 1,482 & 0.0752 & 0.2170 & 0.5357 \\ 1,953 & 0.0957 & 0.2178 & 0.5189\end{array}$

$x_{n-\text { Hexane }}$
0.2523
0.2453
0.2393
0.2333
0.1253
0.1226
0.1198
0.1189
0.1816
0.1767
0.1721
0.1676

KHydrogen
34.66
18.30
12.85
9.80
35.52
20.34
14.04
10.75
34.98
18.52
12.72
10.07

$K_{\text {Benzene }}$

0.1080
0.0636
0.0470
0.0450
0.0917
0.0544
0.0430
0.0377
0.1069
0.0623
0.0480
0.0399

KCyclohexane

$K_{n \text {-Hexane }}$

$\begin{array}{ll}0.1010 & 0.1530 \\ 0.0590 & 0.0888 \\ 0.0433 & 0.0688 \\ 0.0397 & 0.0639 \\ 0.0890 & 0.1417 \\ 0.0530 & 0.0862 \\ 0.0425 & 0.0663 \\ 0.0370 & 0.0571 \\ 0.0895 & 0.1344 \\ 0.0556 & 0.0780 \\ 0.0410 & 0.0626 \\ 0.0350 & 0.0521\end{array}$

.1530

0.0688

0.0639

0.0663

0.0571

.0626

0.0521 
Table 5. Summary of Quaternary Experimental Results at $300^{\circ} \mathrm{F}$.

Pressure,

$\begin{array}{rrrrr}\text { lb./sq. in. abs } & x_{\text {Hydrogen }} & x_{\text {Benzene }} & x_{\text {Cyclohexane }} & x_{n \text {-Hexane }} \\ & & & & \\ 505 & 0.0272 & 0.4022 & 0.3127 & 0.2579 \\ 1,041 & 0.0578 & 0.3896 & 0.3028 & 0.2498 \\ 1,495 & 0.0844 & 0.3786 & 0.2943 & 0.2427 \\ 2,023 & 0.1105 & 0.3678 & 0.2859 & 0.2358 \\ 549 & 0.0277 & 0.4670 & 0.3818 & 0.1235 \\ 1,021 & 0.0530 & 0.4511 & 0.3714 & 0.1245 \\ 1,533 & 0.0793 & 0.4405 & 0.3623 & 0.1179 \\ 2,013 & 0.1018 & 0.4333 & 0.3492 & 0.1157 \\ 512 & 0.0278 & 0.2261 & 0.5649 & 0.1812 \\ 1,019 & 0.0561 & 0.2195 & 0.5485 & 0.1759 \\ 1,503 & 0.0829 & 0.2133 & 0.5329 & 0.1709 \\ 1,921 & 0.1062 & 0.2079 & 0.5193 & 0.1666\end{array}$

$\begin{array}{rr}\text { KHydrogen } & K_{\text {Benzene }} \\ & \\ 29.32 & 0.1980 \\ 15.38 & 0.1073 \\ 10.82 & 0.0859 \\ 8.41 & 0.0715 \\ 29.58 & 0.1769 \\ 16.75 & 0.1148 \\ 11.63 & 0.0806 \\ 9.20 & 0.0673 \\ 29.52 & 0.1827 \\ 16.01 & 0.1060 \\ 11.12 & 0.0847 \\ 8.81 & 0.0750\end{array}$

$0.0640 \quad 0.0923$

into the collecting burette. This mixing step was repeated three times for each hydrocarbon sample. After the pressure, volume, and temperature readings were made, a sample of the hydrocarbon mixture was taken (sample bulb at point $b$ ) and was analyzed on a mass spectrometer.

All hydrocarbons charged to the equilibrium cell were pipetted into the hydrocarbon charging vessel. Thus the hydrogen-free liquid phase composition was known for a given charge. The assumption was made that the composition of a hydrogen-free liquid phase sample should remain close to the known charge composition as sampling progressed. This assumption was very closely checked by mass spectrometer analyses of liquid phase samples as may be seen in Table 2 .

The close agreement between these results was used as a basis for not analyzing a standard known hydrocarbon mixture with each hydrocarbon sample. Samples of each of the three pure hydrocarbons were run each time an analysis was made, however. The results of these analyses served as standards for that day. As the mass spectrometer would show some drift over a period of hours, pure component standards were run immediately proceeding and following all analyses desired for that day. An average value of both start and end results was used to calculate the hydrocarbon analyses.

By using the ideal gas law to calculate the number of moles of the hydrogen and the hydrocarbons present in the liquid phase sample (collecting pressures were always less than 120 $\mathrm{mm} . \mathrm{Hg}$ ) and the results of the mass spectrometer analysis, the liquid phase compositions were then calculated.

The removal of the liquid phase sample from the equilibrium cell caused a drop in the total cell pressure of from $25 \mathrm{lb} . /$ sq.in.abs. at the $2,000 \mathrm{lb} . / \mathrm{sq}$.in.abs. level to $5 \mathrm{lb} . / \mathrm{sq} . i n . a b s$. at the $500 \mathrm{lb} . / \mathrm{sq}$.in.abs. level. No attempt was made to introduce any hydrogen into the cell following this pressure drop to restore the cell pressure to the level that existed prior to sampling. The pressure values reported in this paper are the values that existed prior to liquid phase sampling. It was always found that the cell pressure would increase when the cell stirrer was activated prior to sampling the vapor phase. This would indicate that the liquid phase material remaining in the equilibrium cell had not come to equilibrium at the new slightly lower pressure value, and that the presampling pressure was representative of the true equilibrium pressure.

Prior to sampling the vapor phase, the cell stirrer was turned off and the cell was left undisturbed for at least a $0.5-\mathrm{hr}$. period. The vapor phase sample was handled in much the same manner, except that no samples of the vapor phase were vented. Preliminary runs had shown that consecutive samples of the vapor phase had the same composition and thus it was not necessary to vent vapor phase samples. The cell pressure would then be raised or lowered and again at least a 12-hr. period would be allowed for the system to equilibrate again.

The possibility of condensation occurring in that portion of the vapor phase that was in contact with the magnetic stirrer housing existed. This volume was more than an order of magnitude smaller than the volume available to the vapor in the cell itself, however. The fact that consecutive vapor phase samples showed no composition shifts was used to rule out the possibility of liquid entrainment or the withdrawal of any condensed material from the vapor space in the magnetic stirrer housing.

\section{RESULTS}

Vapor-liquid equilibrium data for the system hydrogenbenzene-cyclohexane- $n$-hexane were obtained for the pressure range 500 to $2,000 \mathrm{lb}$. $/ \mathrm{sq}$. in. abs. and the temperature range $200^{\circ}$ to $300^{\circ} \mathrm{F}$. Three isotherms were run at four pressures, yielding twelve quaternary data points for each initial hydrocarbon charge. Three hydrocarbon charges were run, so a total of thirty-six quaternary equilibrium runs was made. In addition, four runs in both the hydrogen-benzene and hydrogen-cyclohexane systems were made, resulting in a total of forty-four binary and quaternary equilibrium runs. The binary and the quaternary data were determined over the same pressure and temperature range. A summary of the quaternary experimental results obtained at $200^{\circ}, 250^{\circ}$, and $300^{\circ} \mathrm{F}$. is presented in Tables 3, 4, and 5, respectively. The experimental results for the hydrogen-benzene and hydrogen-cyclohexane systems are presented in Table 6.

The quaternary equilibrium data for one of the three liquid charges are graphically presented in Figures 2 through 5. The expression $K$ value used in these figures represents the ratio of the vapor phase mole fraction to the liquid phase mole fraction for the given component. The crosses and dotted lines which appear in Figures 3 to 5 represent the results of the equilibrium ratios as predicted by the modified Chao-Seader correlation. Figures 6 and 7 present the $K$ values of hydrogen for the binary systems studied. The experimental results of Thompson (4) and Connolly (5) are included in these figures for comparison.

Table 6. Summary of Results for Hydrocen-Benzene and Hydrogen-CycloheXane Systems

$\begin{array}{rrrrrr}\begin{array}{c}\text { Pressure, } \\ \text { lb./sq. } \\ \text { in. abs. }\end{array} & \begin{array}{c}\text { Temp., } \\ { }^{\circ} \mathrm{F} .\end{array} & x_{\text {Hydrogen }} & x_{\text {Benzene }} & K_{\text {Hydrogen }} & K_{\text {Benzene }} \\ & & & & & \\ 1,130 & 200 & 0.0332 & 0.9668 & 29.42 & 0.0251 \\ 481 & 200 & 0.0142 & 0.9858 & 67.30 & 0.0463 \\ 2,029 & 300 & 0.0785 & 0.9215 & 12.09 & 0.0548 \\ 532 & 300 & 0.0200 & 0.9800 & 42.53 & 0.1510\end{array}$

$x_{\text {Hydrogen }} x$ Cyclohexane $K_{\text {Hydrogen }} K_{\text {Cyclohexane }}$

$\begin{array}{rrrrrl}2,130 & 200 & 0.0853 & 0.9147 & 11.55 & 0.01620 \\ 550 & 200 & 0.0231 & 0.9769 & 41.53 & 0.0409 \\ 2,017 & 300 & 0.1097 & 0.8903 & 8.65 & 0.0578 \\ 548 & 300 & 0.0300 & 0.9700 & 28.62 & 0.1470\end{array}$




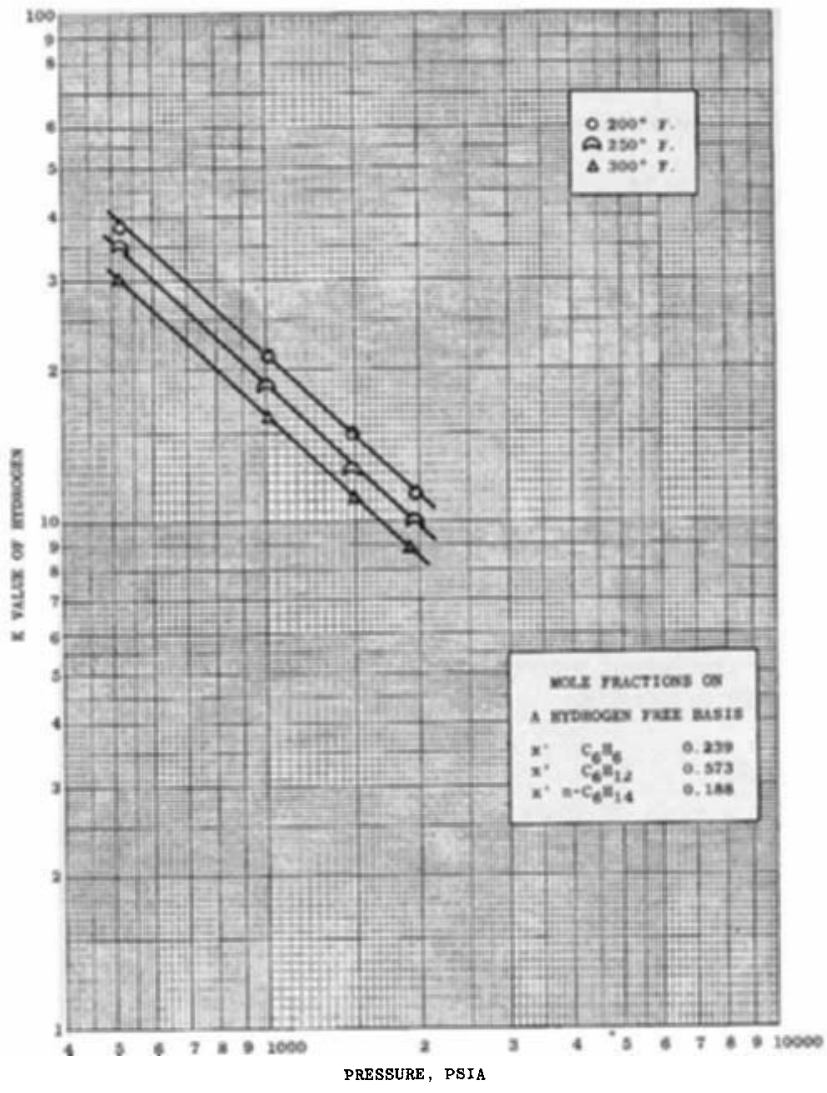

Fig. 2. $K$ volue of hydrogen vs. equilibrium pressure for specified liquid phase.

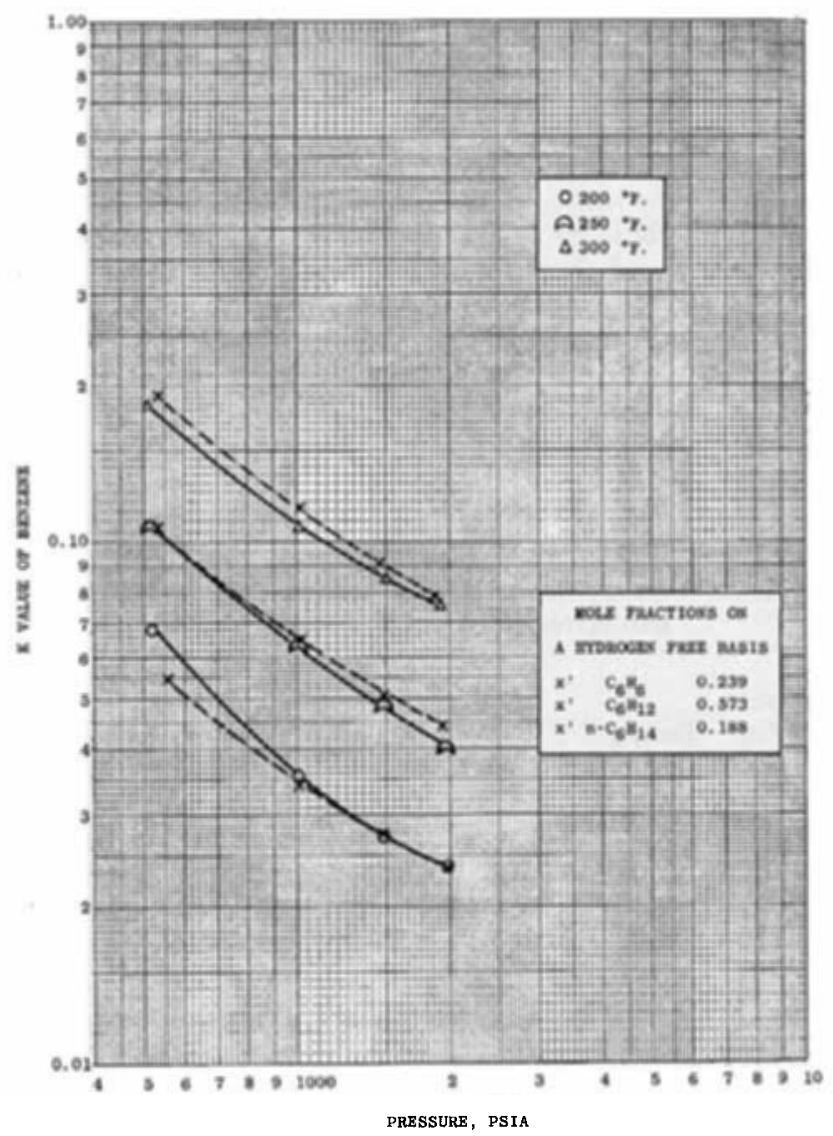

Fig. 3. $K$ value of benzene vs. equilibrium pressure for specified liquid phase.

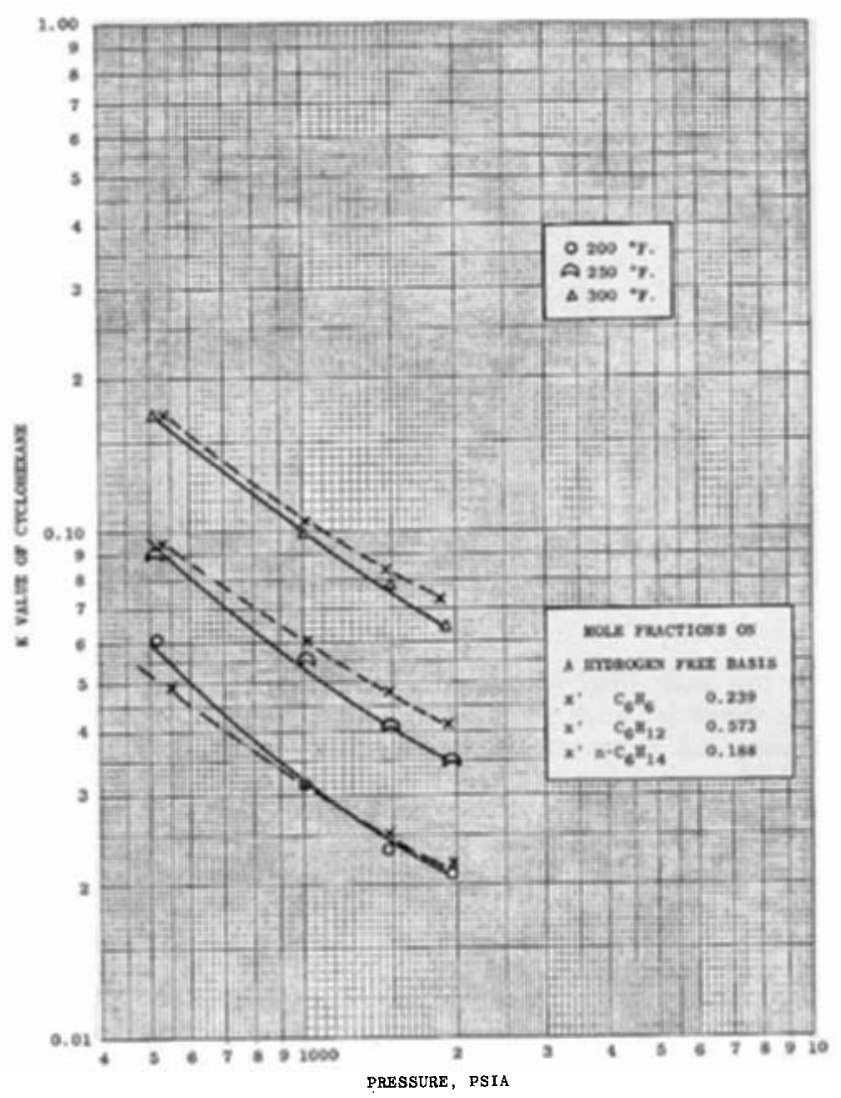

Fig. 4. $K$ value of cyclohexane vs. equilibrium pressure for specified liquid phase.

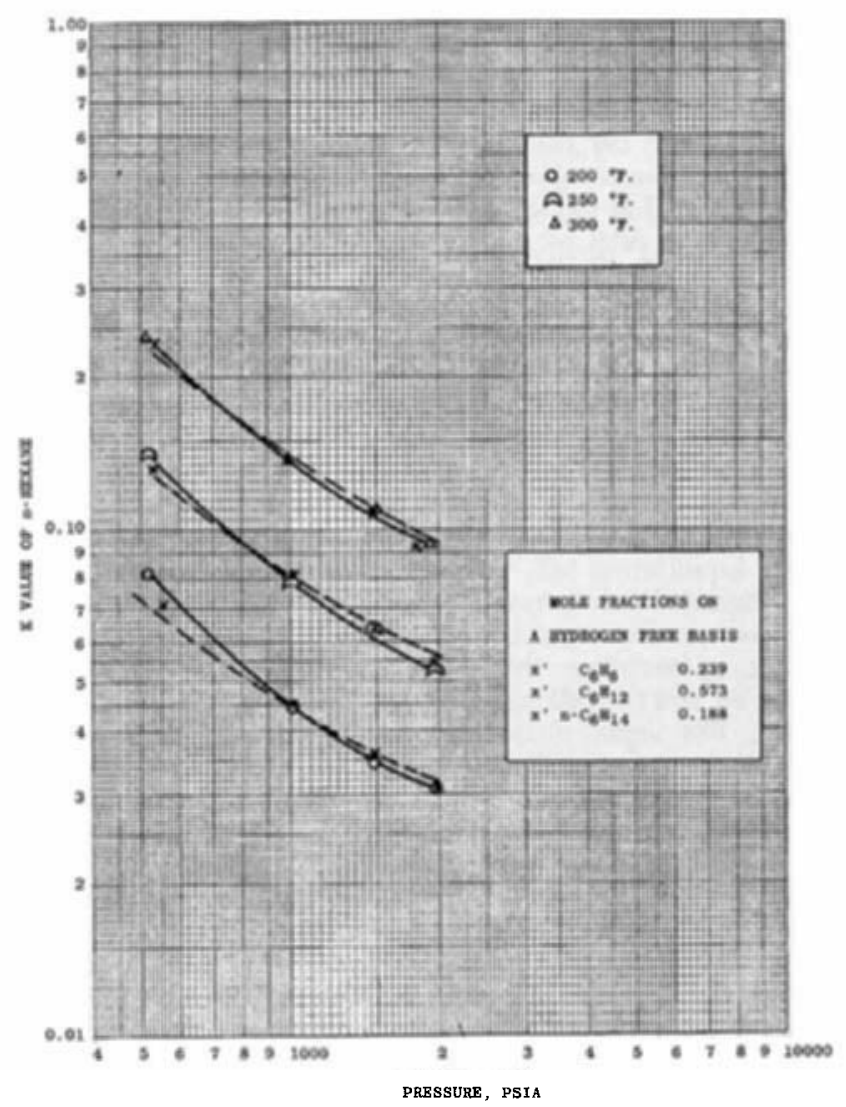

Fig. 5. $K$ value of $n$-hexane vs. equilibrium pressure for specified liquid phase 


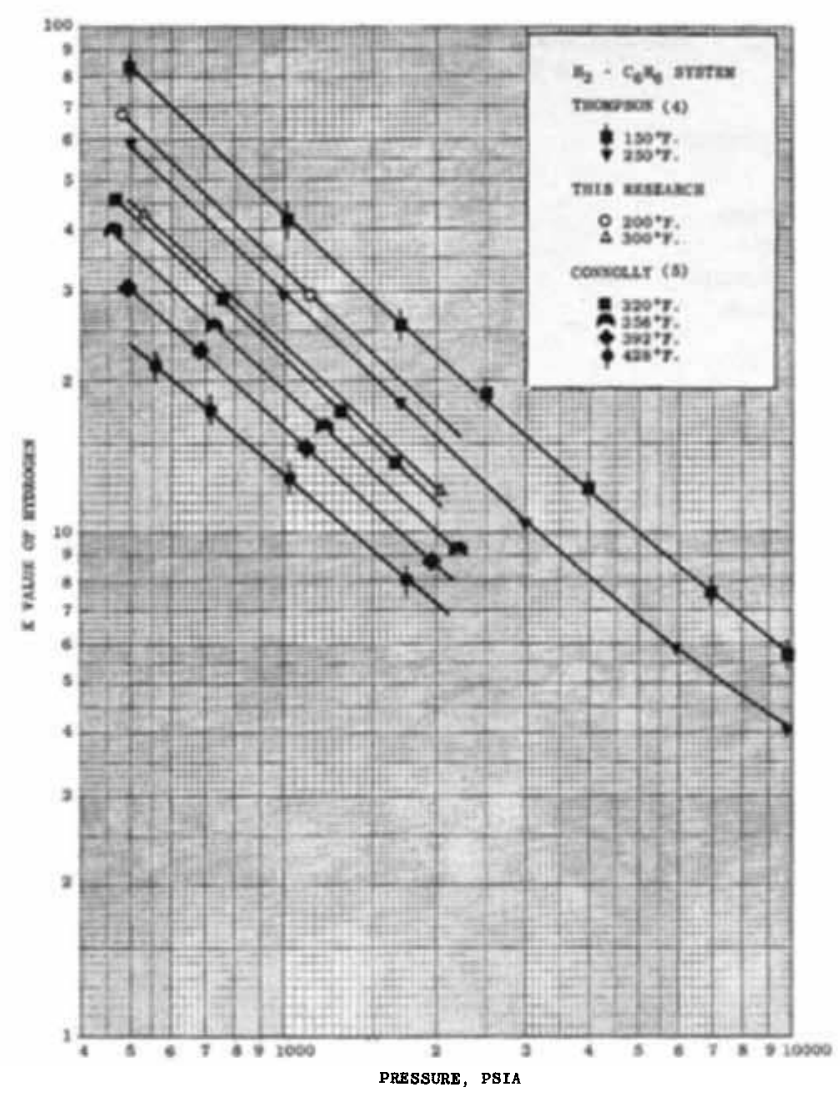

Fig. 6. $K$ value of hydrogen for hydrogen-benzene system.

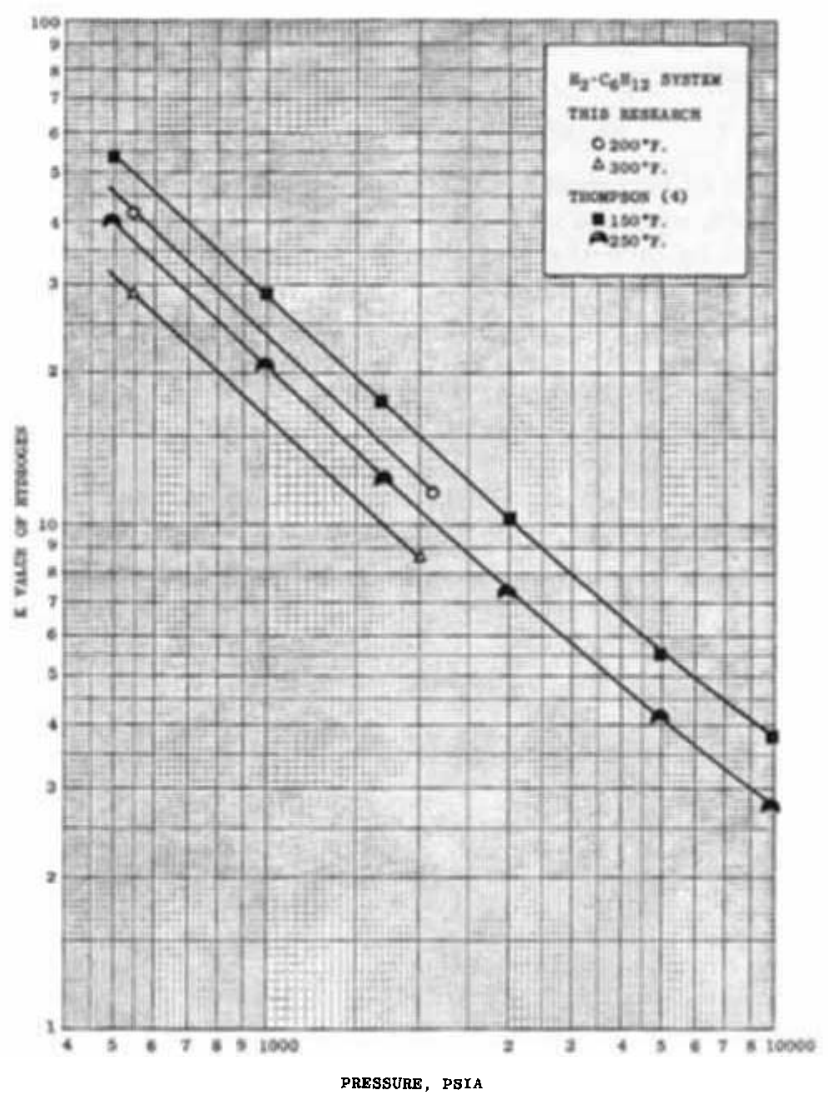

Fig. 7. $K$ value of hydrogen for hydrogen-cyclohexane system.

\section{THERMODYNAMIC TREATMENT AND CORRELATIONS}

By starting with the condition for equilibrium for a two-phase quaternary system at a constant temperature and pressure, which is

$$
\mu_{i}^{L}=\mu_{i}^{V} \quad(i=1,2,3,4)
$$

and by introducing the thermodynamic expressions for fugacity, fugacity coefficient, activity, and activity coefficient, we can derive the following expression for the $K$ value or equilibrium ratio:

$$
K_{i}=\frac{\nu_{i}{ }^{\circ} \gamma_{i}^{L}}{\varphi_{i}} \quad(i=1,2,3,4)
$$

Equation (2), which is the expression used in the ChaoSeader correlation (6), is the starting point for the correlation of the experimental results of this paper. A discussion of the specific method of calculating each of the three terms in Equation (2) now follows.

\section{RELATIONSHIP BETWEEN THE VAPOR PHASE FUGACITY COEFFICIENT $\varphi_{i}$ AND THE VIRIAL EQUATION OF STATE}

The expression which relates the vapor phase fugacity coefficient and the virial coefficients can be written as (7)

$$
\ln \varphi_{i}=\frac{2}{\underline{V}} \sum_{j=1}^{m} y_{i} B_{i j}+\frac{3}{2 \underline{V}^{2}} \sum_{j}^{m} \sum_{k}^{m} y_{i} y_{k} C_{i j k}-\ln Z
$$

Equation (3) is an exact expression for the vapor phase fugacity coefficient subject only to the limitation that the density of the gas must be sufficiently small to neglect the fourth and higher virial coefficients. For the conditions of this research, the terms involving the third and higher order coefficients were neglected.

The Kihara potential was used to evaluate the various terms in Equation (3). Refer to the papers by Kihara (8), Connolly and Kandalic (9), and Prausnitz (7) for detailed coverage of this potential.

Kihara (8) was able to derive the following expression for the second virial coefficient:

$$
\begin{aligned}
B(T) & =\frac{2 \pi}{3} \rho_{o}^{3} F_{3}\left(\frac{U_{o}}{k T}\right)+M_{o \rho_{o}}^{2} F_{2}\left(\frac{U_{o}}{k T}\right) \\
+ & \left(S_{o}+\frac{M_{o}^{2}}{4 \pi}\right) \rho_{o} F_{1}\left(\frac{U_{o}}{k T}\right)+\left(V_{o}+\frac{M_{o} S_{o}}{4 \pi}\right)
\end{aligned}
$$

Kihara (10) extended his original treatment to cover mixtures and derived the following expression for the second virial cross coefficient $B_{A B}(T)$ :

$$
\begin{array}{r}
B_{A B}(T)=\frac{2 \pi}{3} \rho^{3}{ }_{O A B} F_{3}\left(\frac{U_{O A B}}{k T}\right)+\left(\frac{M_{O A}+M_{O B}}{2}\right) \rho^{2}{ }_{O A B} F_{2} \\
\left(\frac{U_{O A B}}{k T}\right)+\left(\frac{S_{O A}+S_{O B}}{2}+\frac{M_{O A} M_{O B}}{4 \pi}\right) \rho_{O A B} F_{1}\left(\frac{U_{O A B}}{k T}\right) \\
+\frac{V_{O A}+V_{O B}}{2}+\frac{M_{O B} S_{O A}+M_{O A} S_{O B}}{8 \pi}
\end{array}
$$

The meaning of the terms $M_{0}, S_{0}$, and $V_{0}$ are given both by Kihara (8) and Prausnitz (7) and therefore will not be repeated here.

The relations for the model parameters

$$
\rho_{o A B}=\frac{\rho_{O A}+\rho_{o B}}{2}
$$

and

$$
U_{O A B}=\left(U_{O A} U_{o B}\right)^{1 / 2}
$$

are recommended by Kihara and Koba (11) and were the 


$\begin{array}{lccclc}\text { Compound } & M_{o} \AA . & \mathrm{S}_{o}, \AA .^{2} & V_{o}, \AA .^{3} & p_{o}, \AA . & \begin{array}{c}U_{o} / k \\ { }^{\circ} \mathrm{K} .\end{array} \\ \text { Hydrogen } & 2.32 & 0 & 0 & 2.81 & 39.4 \\ \text { Benzene } & 13.1 & 10.04 & 0 & 3.40 & 850 \\ \text { Cyclohexane } & 14.53 & 12.28 & 0 & 3.278 & 910 \\ \text { n-Hexane } & 22.6 & 11.2 & 0 & 2.70 & 985\end{array}$

Component

Hydrogen

Benzene

Cyclohexane

n-Hexane $200^{\circ} \mathrm{F}$.

$250^{\circ} \mathrm{F}$.

$300^{\circ} \mathrm{F}$.

3.278
2.70

ones used in this research.

Table 7 lists the model constants used in this work.

The results, with the exception of those for cyclohexane, were obtained from the literature $(7,8$, and 12$)$. The parameters for cyclohexane were determined in this work. The technique used was first to fit the experimental second virial coefficient data for cyclohexane of David (13) to the Kihara potential. Cyclohexane was taken to be a regular hexagon, and an $l$ value ( $l$ is the length of one side of the hexagon and $V_{o}, S_{o}$, and $M_{o}$ are functions of $l$ ) of $1.54 \AA$. was obtained from Bowen (14), and the values of $M_{o}, S_{o}$, and $V_{o}$ were calculated from the following equations:

$$
\begin{aligned}
& M_{o}=3 \pi \\
& S_{o}=\sqrt{3}(3) l^{2} \\
& V_{0}=0
\end{aligned}
$$

Next, trial values of $U_{o} / k$ were selected and $U_{o} / k T$ values were calculated for the temperature range of the experimental second virial coefficient data. Then, by obtaining the $F$ values from the table prepared by Connolly (14), the second virial coefficient values for cyclohexane were calculated for various assumed values of $\rho_{a}$ from Equation (4). By iterating on both the assumed values of $U_{o} / k$ and $\rho_{o}$ and by calculating the standard deviation of the calculated second virial coefficient values from the experimental ones, the values presented in Table 7 for $c y-$ clohexane were found to give the best fit.

The Kihara potential was selected for use because Connolly (12) has shown that the Kihara potential gives an excellent fit of the second mixed virial coefficients for the hydrogen-benzene system.

\section{The Liquid Phase Activity Coefficients}

The following expression was used to calculate the liquid phase activity coefficients:

$$
R T \ln \gamma_{i}=\underline{V_{i}}\left(\delta_{i}-\delta_{M}\right)^{2}
$$

The symbol $\delta_{i}$ is called the solubility parameter and is defined by

$$
\delta_{i} \equiv\left(\frac{\underline{E}_{i}}{\underline{V_{i}}}\right)^{1 / 2}
$$

where $E_{i}$ is the cohesive energy of the $i^{\text {th }}$ component (the energy required to vaporize one mole of pure liquid at zero pressure, and $V_{i}$ is the molal value of the $i^{\text {th }}$ component. $\delta_{M}$ is the volume average value of the solubility parameter for the solution and it is given by

$$
\delta_{M}=\frac{\Sigma_{i} x_{i} \underline{V}_{i} \delta_{i}}{\sum_{i} x_{i} \underline{V}_{i}}
$$

Equations (9), (10), and (11) are the result of the work of Scatchard (16) and Hildebrand (17). The derivation of Equation (9) or its equivalent has been made both by an approach involving the radial distribution functions of statistical thermodynamics (18) and by a treatment in-

volving the cohesive energies of a liquid (16), and will not be repeated here.

Two sources of solubility parameter values were tried in the correlation of the results of this research. First, the solubility parameter values recommended by Chao and Seader (6) were tried. Very large deviations between the experimental results and the predicted values resulted with these values. Next, solubility parameter values were taken from the paper of Prausnitz, Edmister, and Chao (19). These values resulted in a better fit of the experimental results. The solubility parameter values used in this paper were taken from Prausnitz et al. (19) and are given in Table 8.

\section{FUGACITY COEFFICIENT OF THE PURE LIQUID COMPONENT}

Pitzer and Curl (20) have correlated the fugacity coefficient as a function of reduced pressure and reduced temperature by using the acentric factor $\omega$, which is defined by

$$
\omega \equiv-\left(1.000+\log P_{r}^{*}\right)_{T_{r}=0.7}
$$

as a third parameter.

The acentric factor gives a measure of the deviation of the behavior of substances from that of an idealized simple fluid. It is a characteristic constant for each substance. For components that do not exist as liquids at the temperature and the pressure of the system, Chao and Seader (6) have proposed effective fugacity coefficients, which were determined from experimental data. They propose that the relationship

$$
\log \nu_{i}^{o}=\log \nu^{(o)}+\omega^{\prime} \log \nu^{(1)}
$$

be used to represent both actual and effective fugacity coefficients, where $\omega^{\prime}$ is a pseudo acentric factor which was selected to give the best fit of the largest number of experimental data points. The factor $\nu^{(0)}$ is the pure liquid fugacity coefficient of an idealized simple fluid, and is given by an empirical function of $P_{r}$ and $T_{r}$. The factor $\nu^{(1)}$ is also an empirical function of $T_{r}$ and $P_{r}(6)$ and is taken to be a correction term. An additional pressure correction was added to the calculation of $\nu_{i}{ }^{\circ}$ for ben-

\begin{tabular}{|c|c|c|c|c|}
\hline Component & $T_{c},{ }^{\circ} \mathrm{R}$ & $\begin{array}{l}P_{c}, \text { lb./sq. } \\
\text { in. abs. }\end{array}$ & $\frac{V,}{\text { cc./g.-mole }}$ & $\omega^{\prime}$ \\
\hline Hydrogen & 60.2 & 190.8 & 31.0 & 0.0 \\
\hline Benzene & 1012.7 & 714.0 & 89.4 & 0.2130 \\
\hline Cyclohexane & 997.7 & 561.0 & 108.7 & 0.2032 \\
\hline$n$-Hexane & 914.2 & 440.0 & 131.6 & 0.2927 \\
\hline
\end{tabular}
zene, clycohexane, and $n$-hexane. This correction, which is merely intended to be a first-order correction, was necessary to obtain better agreement between the correlated and the experimental results. The following equations were used to correct the $\nu_{i}{ }^{\circ}$ values:

Table 9. Physical Constants and Parameters

The $\omega^{\prime}$ and $\underline{V}$ values are those given in the Chao-Seader paper. 


\begin{tabular}{|c|c|c|c|c|c|}
\hline \multirow{2}{*}{$\begin{array}{l}P, \text { lb./sq. } \\
\text { in. abs. }\end{array}$} & \multicolumn{4}{|c|}{$200^{\circ} \mathrm{F}$. } & \multirow[b]{2}{*}{$\varphi 1$} \\
\hline & $\varphi 1$ & $\varphi 2$ & $\varphi 3$ & $\varphi 4$ & \\
\hline 500 & 1.058 & 0.898 & 0.892 & 0.896 & 1.068 \\
\hline 1,000 & 1.078 & 0.874 & 0.868 & 0.876 & 1.090 \\
\hline 1,500 & 1.100 & 0.850 & 0.845 & 0.856 & 1.113 \\
\hline 2,000 & 1.220 & 0.827 & 0.822 & 0.837 & 1.135 \\
\hline \multicolumn{6}{|c|}{$\begin{aligned} \nu^{\circ} \mathrm{C}_{6} \mathrm{H}_{6}=\nu^{\circ} \mathrm{C}_{6} \mathrm{H}_{6} \quad \text { (Chao, Seader)/ } & \left(1.00+5.0 \times 10^{-5} \times \mathrm{P}\right)\end{aligned}$} \\
\hline \multicolumn{6}{|c|}{$\nu^{\circ} \mathrm{C}_{6} \mathrm{H}_{12}=\nu^{\circ} \mathrm{C}_{6} \mathrm{H}_{12}$ (Chao, Seader) $/\left(1.00+5.0 \times 10^{-5} \times \mathrm{P}\right)$} \\
\hline \multicolumn{6}{|c|}{$\begin{aligned} \nu^{0} n-\mathrm{C}_{6} \mathrm{H}_{14}=\nu^{\circ} n-\mathrm{C}_{6} \mathrm{H}_{14} \text { (Chao, Seader) } / \\
\left(1.05+1.20 \times 10^{-4} \times \mathrm{P}\right)\end{aligned}$} \\
\hline
\end{tabular}

Table 9 lists some physical constants and parameters used in this correlation.

The calculation procedure followed was to fix the hydrocarbon liquid phase compositions and the temperature at their experimental values (this fixes the four intensive variables required by the phase rule for a twophase, four-component system), and to use the experimental pressure and vapor compositions as first trial values. With these values, Equations (3), (9), (13), and (2) were used to calculate the equilibrium ratios. Next, the $\Sigma y_{\text {icalc. }}$ were calculated:

$$
\sum_{i=1}^{4} y_{\text {icalc. }}=\sum_{i=1}^{4} x_{i} K_{i \text { calc. }}
$$

The convergence test was to require

$$
\left|\sum_{i=1}^{4} y_{\text {icalc. }}-1\right|<0.0005
$$

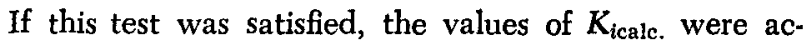
cepted. If the test failed, however, new trial values of $y_{i}$ were selected along with a new pressure value and the calculations were repeated. The new trial pressure was calculated from the following equation:

$$
(P)_{\text {trial } n+1}=(P)_{\text {trial } n}+\left(\sum_{i}^{\Sigma} y_{\text {calc. } i_{\text {trial }}}-1\right) \times \epsilon
$$

This equation would increase the next trial pressure for those cases where $\Sigma_{i} y_{\text {calc. } i}>1$ and would decrease the next trial pressure for those cases where $\sum_{i} y_{\text {calc }, i}<1$. This was of course in keeping with the known behavior of the physical system. Each time that a new trial pressure was used, the trial values for the vapor phase compositions were also changed according to the following equations:

$$
\begin{aligned}
& \left(y_{1}\right)_{\text {trial } n+1}=\left(y_{1}\right)_{\text {trial } n}+0.0003 \\
& \left(y_{i}\right)_{\text {trial } n+1}=\left(y_{i}\right)_{\text {trial } n}-0.0001(i=2,3,4)
\end{aligned}
$$

for the case were $\left(\underset{i}{\Sigma_{i}} y_{\text {calc. } i \text { trial }}<1\right)$ and the equations

$$
\begin{aligned}
& \left(y_{1}\right)_{\text {trial } n+1}=\left(y_{1}\right)_{\text {trial } n}-0.0003 \\
& \left(y_{i}\right)_{\text {trial } n+1}=\left(y_{i}\right)_{\text {trial } n}+0.0001(i=2,3,4)
\end{aligned}
$$

for the case where $\left(\Sigma y_{\text {calc. } i \text { trial }} n>1\right)$. Various values of $\epsilon$ were tried but the results were not found to be very sensitive to this parameter. An $\epsilon$ value of 400 was used in this paper. Conversion was very rapid with this technique $250^{\circ} \mathrm{F}$.

$\varphi 2 \varphi \varphi s \quad \varphi$

$\varphi 4 \varphi 1$

$300^{\circ} \mathrm{F}$.

$\begin{array}{lll}0.882 & 0.872 & 0.870\end{array}$

$\begin{array}{lll}0.860 & 0.852 & 0.854\end{array}$

$\begin{array}{lll}0.840 & 0.832 & 0.838\end{array}$

$\begin{array}{lll}0.818 & 0.811 & 0.821\end{array}$

$\begin{array}{lll} & & \varphi 3 \\ 1.100 & 0.842 & 0.829 \\ 1.120 & 0.825 & 0.810 \\ 1.144 & 0.809 & 0.793 \\ 1.167 & 0.792 & 0.776\end{array}$

$\varphi 4$

0.826

0.813

0.799

0.785

as Equation (16) was satisfied in fourteen trials or less for all cases. The results of this correlation (for one liquid charge) are shown as the dotted lines in Figures 3 through 5 . The absolute average deviation of all experimental results for all components is $4.86 \%$.

\section{Vapor Phose Fugacity Volues}

Representative values for the vapor phase fugacities calculated from Equation (3) by using the experimental equilibrium pressure and the experimental vapor compositions are shown in Table 10.

The values presented in Table 10 are all for a given hydrocarbon charge and were obtained from cross plots of the $\varphi_{i}$ values vs. pressure for the given isotherms. There was a very small effect of composition on the hydrocarbon $\varphi_{i}$ values-less than $2 \%$ for the composition range studied. The hydrogen vapor phase fugacity values showed greater composition dependence, however. By examining the $\varphi_{1}$ results from the three hydrocarbon charges, it was found that the $\varphi_{i}$ value for hydrogen increased as the liquid phase concentration of hexane increased. This is believed to be a consequence of the fact that the second virial cross coefficient $B_{1,4}$ was positive and larger than $B_{1,2}$ and $B_{1,3}$. Inspection of Equation (3) written for $\varphi_{1}$ shows that as more hexane enters the vapor phase, $\varphi_{1}$ will increase. The effect of composition on $\varphi_{1}$ values was less than $8 \%$ for the conditions of this study.

\section{EFFECT OF HYDROCARBON LIQUID PHASE COMPOSITION ON THE EQUILIBRIUM RATIOS}

The three hydrocarbon charges used in this research had a definite relationship to one another as may be seen from Table 11.

In charges 1 and 2 of Table 11 the mole ratio of benzene to cyclohexane was maintained constant, while in charges 2 and 3 the mole ratio of cyclohexane to $n$-hexane was maintained the same. No strong effect of liquid phase composition on any of the hydrocarbon equilibrium ratios was noted for the range of compositions studied in this research. Whether this would still be true over all possible composition ranges is not known.

A definite liquid phase composition effect on the equilibrium ratio of hydrogen was noted, however. Figures 8 and 9 show this composition effect. The binary points in these figures, of course, represent the limiting case for the quaternary system. A qualitative understanding of the slopes shown in these figures (positive or negative) results from a consideration of the solubility of hydrogen in the various binaries. For example, the solubility of hydro-

Table 11. Liquid Phase Hydrogen Free Mole Ratios

Mole ratio

Benzene/Cyclohexane Cyclohexane/n-Hexane Charge No.

$\begin{array}{lll}1.21 & 1.31 & 1 \\ 1.21 & 3.05 & 2 \\ 1.42 & 3.05 & 3\end{array}$




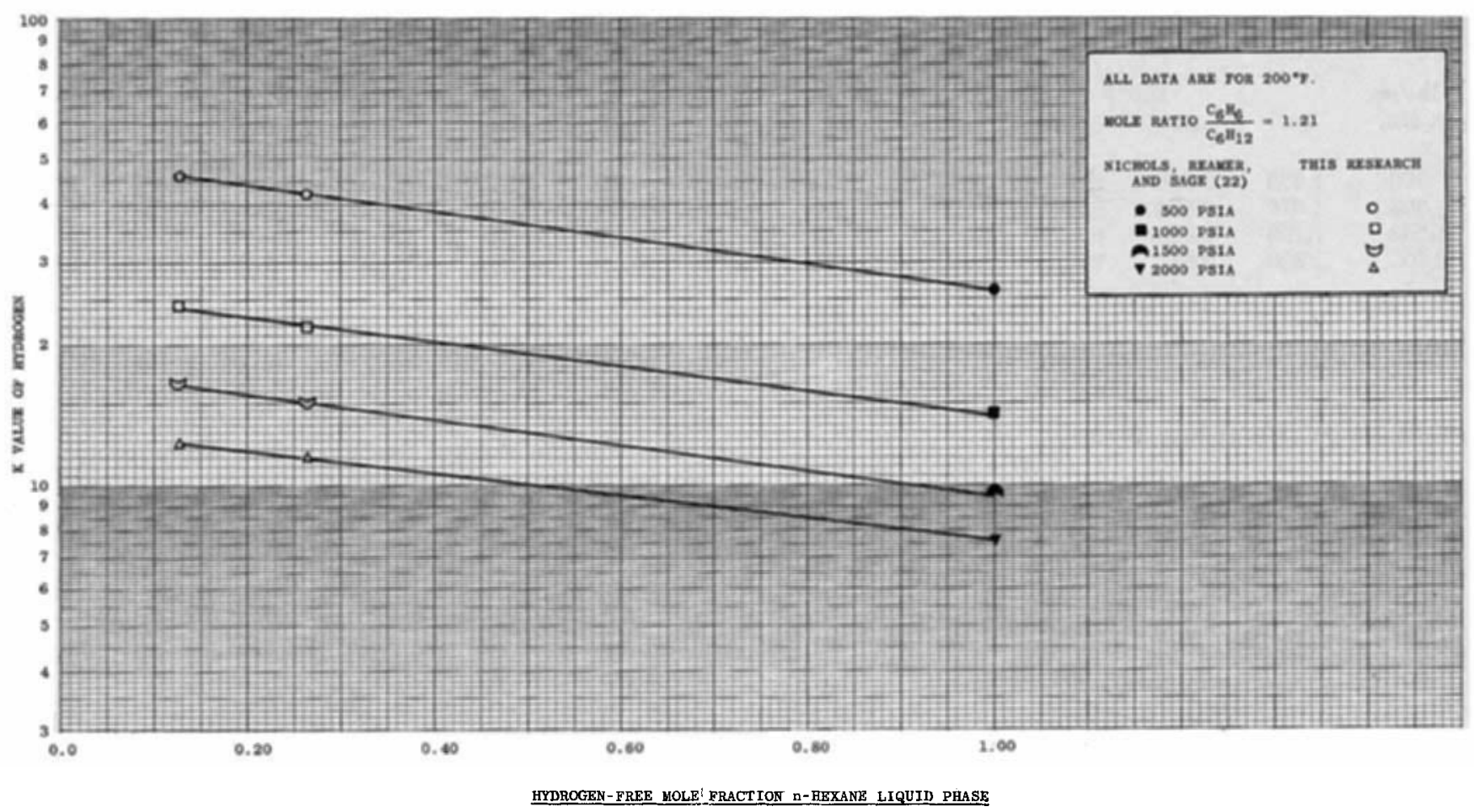

Fig. 8. $K$ value of hydrogen vs, $n$-hexane liquid phase composition.

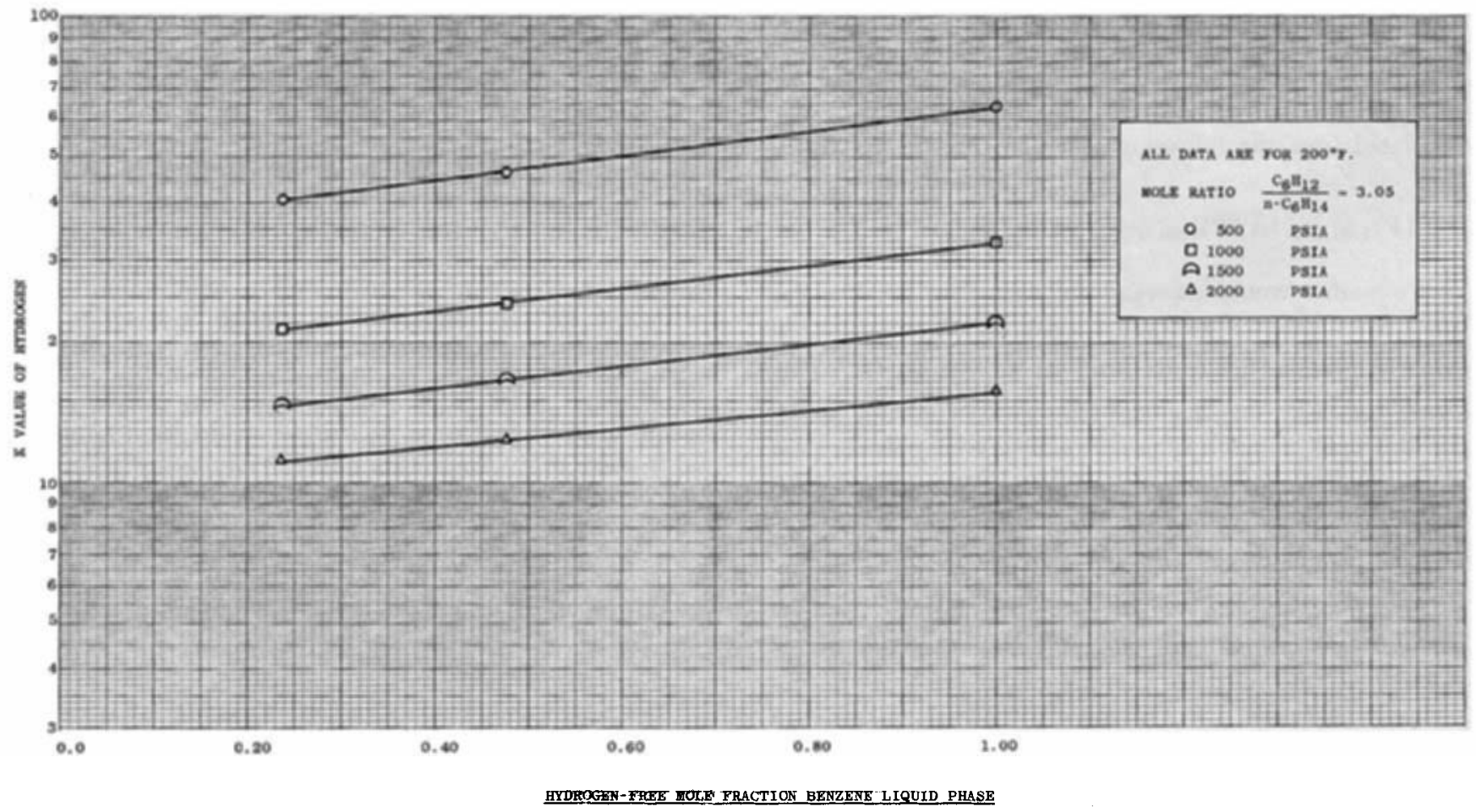

Fig. 9. $K$ value of hydrogen vs. benzene liquid phase composition. 
gen in the three hydrocarbons follows the behavior solubility $n-\mathrm{C}_{6} \mathrm{H}_{14}>$ solubility $\mathrm{C}_{6} \mathrm{H}_{12}>$ solubility $\mathrm{C}_{6} \mathrm{H}_{6}$

for a constant temperature (21). Thus, by adding benzene and cyclohexane to the liquid phase composed of hydrogen and $n$-hexane, we lower the value of $x_{\mathrm{H}_{2}}$ and correspondingly increase the $K$ value of hydrogen. (This analysis has been made by neglecting the effect of the addition of benzene and cyclohexane to the vapor phase). Figure 8 shows the behavior just described. By similar reasoning the behavior shown in Figure 9 can also be explained. While Figures 8 and 9 are for the one temperature of $200^{\circ} \mathrm{F}$, similar behavior was found for the other two isotherms of this study.

\section{SUMMARY AND CONCLUSIONS}

A computer program based on a modified version of the Chao-Seader correlation has been developed to predict the values of the equilibrium ratios for the thirty-six quaternary equilibrium points presented in this research. The program predicts well the data and gives an average absolute deviation of $\mathbf{4 . 8 6}$ for the one hundred forty-four data points tested.

An inspection of Equation (2) reveals that the failure of a prediction technique based on this equation could be the result of an inability to represent properly any one of the three terms $\gamma_{i}, \nu_{i}{ }^{\circ}$, and $\varphi_{i}$ by prediction techniques. Of these terms it is felt that the term for the vapor phase fugacity coefficient $\varphi_{i}$ can be treated most satisfactorily by the tools of statistical thermodynamics. The evaluation of the other terms, $\gamma_{i}$ and $\nu_{i}^{o}$, involves the use of an oversimplified treatment of the liquid phase in the one case and an empirical approach in the other. The fact that a theory giving an adequate quantitative description of the liquid phase has not been presented has proven to be the largest obstacle.

\section{ACKNOWLEDGMENT}

The Phillips Petroleum Company donated the hydrocarbons used in this study, Esso Research and Engineering provided funds for two summer fellowships, and Frank Drogosz ran the mass spectrometer analyses.

\section{NOTATION}

$B=$ second virial coefficient for a pure component, cu. ft./lb.-mole

$C=$ third virial coefficient for a pure component, $\mathrm{ft}^{6} /$ (lb.-mole $)^{2}$

$E=$ cohesive energy, cal.

$F_{1}, F_{2}, F_{3}=$ functions used in Kihara core model

$K=$ equilibrium ratio

$k=$ Boltzmann constant

$l \quad=$ intermolecular distance in Kihara core model

$M_{o}=$ mean curvature for convex core in Kihara core model, $\AA$.

$m \quad=$ number of components

$P \quad=$ pressure, lb./sq. in. abs.

$R \quad=$ ideal gas law constant

$r=$ distance between centers of molecules or atoms

$r_{\boldsymbol{e}}=$ separation between molecules or atoms when there is zero force between them

$S_{o}=$ surface area in Kihara core model, $\AA^{2}{ }^{2}$

$T=$ absolute temperature

$U_{o}=$ scalar magnitude of intermolecular potential energy at $r=r_{e}$

$V=$ volume

$V_{0}=$ volume in Kihara core model, $\AA^{3}{ }^{3}$

$x=$ mole fraction liquid phase

$y=$ mole fraction vapor phase

$z=$ compressibility factor, dimensionless

\section{Greek Letters}

€ $=$ parameter used to correct trial pressure

$\gamma=$ activity coefficient

$\delta \quad=$ solubility parameter, $(\text { cal. } / \text { cc. })^{1 / 2}$

$\mu \quad=$ chemical potential

$\nu^{0}=$ liquid phase fugacity coefficient for a pure component

$\nu^{(o)}, \nu^{(1)}=$ empirical functions used to evaluate $\nu^{\circ}$

$\rho_{o}=$ parameter in Kihara core model

$\varphi=$ vapor phase fugacity coefficient

$\omega \quad=$ acentric factor

$\omega^{\prime} \quad=$ pseudo acentric factor

\section{Subscripts}

$A, B, A B=$ components $A$ and $B$ and $A-B$ pair

$C=$ critical property

calc. $=$ calculated quantity

$i, j, k=$ component designation

$M \quad=$ property of a mixture

$r \quad=$ reduced property

- = molar quantity

$1,2,3,4=$ hydrogen, benzene, cyclohexane, and $n$-hexane, respectively

Superseripts
$\begin{aligned} L \quad=\text { liquid phase } \\ V \quad=\text { vapor phase } \\ O \quad=\text { pure component property } \\ , \quad=\text { composition on a hydrogen-free basis } \\ \text { * } \quad=\text { vapor pressure }\end{aligned}$

\section{LITERATURE CITED}

1. "Engineering Data Book," 7 ed., Natl. Gasoline Supply Men's Assoc., Tulsa, Okla. (1957).

2. "Kellogg Equilibrium Charts," M. W. Kellogg Co., New York.

3. Hougen, O. A., K. M. Watson, and R. A. Ragatz, "Chemical Process Principles," 2 ed., Pt. II, p. 942, Wiley, New York (1959).

4. Thompson, R. E., and W. C. Edmister, A.I.Ch.E. J., 11, No. 3, 457-461 (1965).

5. Connolly, J. F., J. Chem. Phys., 36, No. 11, 2897-2904 (1962).

6. Chao, K. C., and J. D. Seader, A.I.Ch.E. J., 7, No. 4, 598-606 (1961).

7. Prausnitz, J. M., and R. N. Keeler, ibid., No. 3, 399-405 (1961)

8. Kihara, T., Rev. Mod. Phys., 25, No. 4, 831-843 (1953).

9. Connolly, J. F., and G. A. Kandalic, Phys. Fluids, 3, No. 3, 463-467 (1960).

10. Kihara, T., Rev. Mod. Phys., 27, No. 4, 412-423 (1955).

11.

12. Connolly, J. F., Phys. Fluids, 4, No. 12, 1494-1499 (1961).

13. David, H, G., S. D. Hamann, and R. B. Thomas, Australian J. Chem., 12, No. 3, 309 (1959).

14. Bowen, H. J. M., et al., "Tables of Interatomic Distances and Configuration in Molecules and Ions," Chem. Soc,, London, England (1958),

15. Connolly, J. F., Document No. 6307, Documentation Inst. Lib. Congr.

16. Scatchard, G., Chem. Rev., 8, No. 2, 321-333 (1931).

17. Hildebrand, J. H., and R. L. Scott, "Regular Solutions," Prentice-Hall, Englewood Cliffs, N. J. (1962).

18. Hildebrand, J. H., and S. E. Wood, J. Chem. Phys., 1, No. 12, 817-822 (1933).

19. Prausnitz, J. M., W. C. Edmister, and K. C. Chao, A.I.Ch.E. J., 7, No. 3, 399-405 (1961).

20. Pitzer, K. S., and R. F. Curl, J. Am. Chem. Soc., 79, 2369 (1957).

21. Sattler, H., Z. Tech. Phys., 21, 410-413 (1940).

22. Nichols, W. B., H. H. Reamer, and B. H. Sage, A.I.Ch.E. J., 3, No. 2, 262-267 (1957).

Manuscript received October 19, 1965; revision received May 17, 1966; paper accepted May 27, 1966. 